\title{
Stroke prevention in atrial fibrillation
}

\section{Commentary regarding the AAN's evidence- based guideline update}

\author{
Robert G. Hart, MD \\ John W. Eikelboom, MBBS
}

A

trial fibrillation is a common, potentially preventable cause of disabling stroke in the elderly, particularly in elderly women, resulting from embolism of stasis-precipitated thrombi formed in the left atrial appendage. In 1989, the first randomized clinical trial of anticoagulant therapy in atrial fibrillation showed that warfarin produced a large reduction in ischemic stroke. ${ }^{1}$ In the ensuing 25 years, more than 40 additional randomized trials have permitted stroke prophylaxis to be importantly refined. It has been a period of remarkable progress in stroke prevention. Here, we discuss selected aspects of the American Academy of Neurology (AAN)'s evidence-based guideline update. ${ }^{2}$

The most salient area of progress during the past decade has been the advent of the direct-acting oral anticoagulants (dabigatran, rivaroxaban, apixaban, edoxaban) that have revolutionized anticoagulant management. These agents selectively inhibit factor Xa (names ending in "Xaban"rivaroxaban, apixaban, edoxaban) or thrombin (names ending in "tran"- dabigatran) and have been referred to as the "novel oral anticoagulants." However, the novel oral anticoagulants are no longer new; initial phase III randomized trials testing an oral direct thrombin inhibitor in atrial fibrillation were published a decade ago. What distinguishes these agents from oral vitamin $\mathrm{K}$ antagonists is that they directly interact with their coagulation protein target, and thus we propose that the term direct-acting oral anticoagulant (DOACs) is more useful.

In patients with atrial fibrillation, DOACs sharply reduce the risk of intracranial hemorrhage compared with high-quality warfarin anticoagulation, and it is this effect that accounts for much of their benefits over warfarin. ${ }^{3}$ Despite these benefits, DOACs are not simply "warfarin-made-easy" and do not work as well as warfarin in patients with mechanical heart valves. ${ }^{4}$ It took nearly 50 years to optimize warfarin dosing, monitoring, and reversal of the anticoagulant effect, and improvements in the clinical use of the DOACs are anticipated.

Culebras et al. ${ }^{2}$ have recently updated the 1998 AAN guideline on prevention of stroke in nonvalvular atrial fibrillation. Weighing the evidence is always challenging, and it is often difficult to reach agreement even between experienced clinician scientists following detailed rules of evidence. That stated, our views differ with the updated guideline in 3 important management areas.

Atrial fibrillation patients with prior stroke or TIA have a high risk of ischemic stroke (about $10 \%$ per year) if not anticoagulated. The European Atrial Fibrillation Study demonstrated a large reduction in stroke when such patients are treated with oral vitamin $\mathrm{K}$ antagonists, ${ }^{5}$ confirmed by significant reductions among subgroups of participants with prior stroke/TIA

McMaster University/Population Health Research Institute, Hamilton Health Sciences, Hamilton, Canada. Funding information and disclosures are provided at the end of the article. Full disclosure form information provided by the authors is available with the full text of this article at Neurology.org/cp.

Correspondence to: robert.hart@phri.ca 
in other randomized trials ${ }^{6,7}$ and by meta-analyses. ${ }^{8,9}$ Hence, the Level B recommendation ("should") attached to recommendation for anticoagulation of atrial fibrillation patients with prior stroke or TIA in the current guideline is too tepid. Atrial fibrillation patients with prior ischemic stroke or TIA benefit the most from anticoagulation and should receive anticoagulation if it can be given safely. The strength and consistency of evidence from multiple randomized trials are overwhelming, and we would rate the recommendation for anticoagulation higher (Level A, "must").

The updated guideline recommends several options for oral anticoagulation of atrial fibrillation patients that include warfarin, dabigatran, rivaroxaban, and apixaban, and favors the use of DOACs for those "at higher risk of intracranial bleeding" (not clearly specified). DOACs, when available and affordable, should be preferred over warfarin for most patients with atrial fibrillation. This includes atrial fibrillation patients with prior stroke or TIA based on metaanalyses of subgroups of patients with prior brain ischemia included in the large phase III trials comparing DOACs with warfarin. ${ }^{10,11}$ This "DOAC instead of warfarin" recommendation (with caveats) is in line with several recent, prominent evidence-based guidelines. ${ }^{12-14}$ The recently published large randomized trial comparing edoxaban with warfarin adds to the weight of evidence favoring DOACs as the anticoagulants of choice for most atrial fibrillation patients with good renal function. ${ }^{15}$

Triflusal plus acenocoumarol (target international normalized ratio [INR] 1.25-2.0) is advocated ("triflusal plus acenocoumarol is likely more effective than acenocoumarol alone in reducing stroke risk") in the updated guideline as an option for atrial fibrillation patients with moderate stroke risk, particularly in developing countries. This recommendation is based on a single, relatively small, open-label randomized trial that demonstrated no statistically significant effect on stroke. ${ }^{16}$ Recommendation to use triflusal plus low-intensity acenocoumarol for stroke prevention in atrial fibrillation patients is premature, particularly considering the much higher quality data supporting alternative treatments.

A hot topic addressed in the updated guideline is how optimally to detect covert paroxysmal atrial fibrillation in patients with recent brain ischemia. Extended cardiac rhythm monitoring of patients with recent "cryptogenic" brain ischemia reveals evidence of atrial fibrillation in $10 \%-20 \%$, with longer periods of monitoring rendering higher yields. However, it remains unclear whether relatively brief episodes of atrial fibrillation (e.g., lasting only a few minutes or even seconds) during prolonged continuous cardiac monitoring identifies patients at high risk for subsequent stroke that would be prevented by anticoagulation. All of the studies completed to date have lacked a control group of elderly patients without stroke. In short, when you look vigorously for atrial fibrillation in patients with recent ischemic stroke, you often find it, but the threshold duration of atrial fibrillation that identifies patients who will benefit from anticoagulation has yet to be determined, a vexing conundrum for clinicians. The current AAN guideline includes the recommendation that "clinicians might obtain outpatient cardiac rhythm studies in patients with cryptogenic stroke to identify patients with occult NVAF (Level C)." We agree and look forward to additional studies that will allow stronger and more specific recommendations.

\section{REFERENCES}

1. Petersen P, Boysen G, Godtfredsen J, Andersen ED, Andersen B. Placebo-controlled, randomized trial of warfarin and aspirin for prevention of thromboembolic complications in chronic atrial fibrillation: the Copenhagen AFASAK study. Lancet 1989;1:175-179.

2. Culebras A, Messé SR, Chaturvedi S, Kase CS, Gronseth G. Summary of evidence-based guideline update: Prevention of stroke in nonvalvular atrial fibrillation: Report of the Guideline Development Subcommittee of the American Academy of Neurology. Neurology 2014;82:716-724.

3. Chatterjee S, Sardar P, Biondi-Zoccai G, Kumbhani DJ. New oral anticoagulants and the risk of intracranial hemorrhage: insights from a traditional and Bayesian meta-analysis and mixed treatment comparison of randomized trials of new oral anticoagulants in atrial fibrillation. JAMA Neurol Epub 2013 Oct 28. 
4. Eikelboom JW, Connolly SJ, Bruekmann M, et al. Dabigatran versus warfarin in patients with mechanical heart valves. N Engl J Med 2013;369:1206-1214.

5. European Atrial Fibrillation Trial Study Group. Secondary prevention in non-rheumatic atrial fibrillation after transient ischemic attack or minor stroke. Lancet 1993;342:1255-1262.

6. Stroke Prevention in Atrial Fibrillation Investigators. Adjusted-dose warfarin versus low-intensity, fixed-dose warfarin plus aspirin for high-risk patients with atrial fibrillation: the Stroke Prevention in Atrial Fibrillation III randomized clinical trial. Lancet 1996;348:633-638.

7. Connolly SJ, Eikelboom J, Joyner C, et al. Effect of apixaban in patients with atrial fibrillation. N Engl J Med 2011;364:806-817.

8. van Walraven C, Hart RG, Singer DE, et al. Oral anticoagulants vs aspirin in nonvalvular atrial fibrillation: an individual patient meta-analysis. JAMA 2002;288:2441-2448.

9. Hart RG, Pearce LA, Aguilar MI. Meta-analysis: antithrombotic therapy to prevent stroke in patients who have nonvalvular atrial fibrillation. Ann Intern Med 2007;146:857-867.

10. Ntaios G, Papavasileiou V, Diener H-C, Makaritsis K, Michel P. Nonvitamin-K-antagonist oral anticoagulants in patients with atrial fibrillation and previous stroke or transient ischemic attack: a systematic review and meta-analysis of randomized controlled trials. Stroke 2012;43:3298-3304.

11. Ruff CT, Giugliano RP, Braunwald E, Hoffman EB, Deenadayalu N, Ezekowitz MD. Comprehensive meta-analysis comparing the efficacy and safety of new oral anticoagulants with warfarin in atrial fibrillation: an analysis including 71,683 subjects from four large randomized clinical trials. Lancet Epub 2013 Dec 4.

12. Camm AJ, Lip GYH, De Caterina R, et al. 2012 focused update of the ESC Guidelines for the management of atrial fibrillation. Eur Heart J 2012;33:2719-2747.

13. Skanes AC, Healey JS, Cairns JA, et al. Focused 2012 Update of the Canadian Cardiovascular Society Atrial Fibrillation Guidelines: recommendations for stroke prevention and rate/rhythm control. Can J Cardiol 2012;28:125-136.

14. You JJ, Singer DE, Howard PA, et al. Antithrombotic therapy for atrial fibrillation: antithrombotic therapy and prevention of thrombosis, 9th ed: American College of Chest Physicians evidence-based clinical practice guidelines. Chest 2012;141:e531S-e575S.

15. Giugliano RP, Ruff CT, Braunwald E, et al; for the ENGAGE AF-TIMI 48 Investigators. Edoxaban versus warfarin in patients with atrial fibrillation. N Engl J Med 2013;369:2093-2104.

16. Pérez-Gómez F, Alegría E, Berjón J, Iriarte JA, Zumalde J, Salvador A; for the NASPEAF Investigators. Comparative effects of antiplatelet, anticoagulant, or combined therapy in patients with valvular and nonvalvular atrial fibrillation: a randomized multicenter study. J Am Coll Cardiol 2004;44:1557-1566.

\section{STUDY FUNDING}

No targeted funding reported.

\section{DISCLOSURES}

R.G. Hart has received research support from Bayer Pharmaceuticals and NIH/National Institute of Neurological Disorders and Stroke. J.W. Eikelboom serves on scientific advisory boards for Rocket-AF, Hokusai, Bayer, Boehringer-Ingelheim, Bristol Myers-Squibb/Pfizer, and Daiichi Sankyo; has received consulting fees and honoraria from Astra-Zeneca, Bayer, Boehringer-Ingelheim, Bristol Myers-Squibb, Daiichi-Sankyo, Eli-Lilly, GlaxoSmithKline, Pfizer, Janssen, and Sanofi-Aventis; serves on the editorial board of Thrombosis and Haemostasis; uses oral anticoagulants on a regular basis for treatment of venous thromboembolism and atrial fibrillation (Thrombosis Unit, Hamilton General Hospital, 25\% clinical effort); and receives research support from Astra-Zeneca, Bayer, Boehringer-Ingelheim, Bristol MyersSquibb, GlaxoSmithKline, Pfizer, Janssen, Sanofi-Aventis, Canadian Institute for Health Research, Heart and Stroke Foundation of Ontario, National Health and Medical Research Council, and New Investigator Fund, Hamilton Health Sciences. Full disclosure form information provided by the authors is available with the full text of this article at Neurology.org/cp.

\section{ERRATUM}

Management of unruptured intracranial aneurysms

In the article "Management of unruptured intracranial aneurysms" by Lindsy N. Williams and Robert D. Brown, Jr. (Neurol Clin Pract 2013;3:99-109), there is an omission in the legends of figures 1 and 2. There should be an additional sentence that reads: "Used with permission of Mayo Foundation for Medical Education and Research, all rights reserved.” The editorial staff regrets the omission. 


\title{
Neurology ${ }^{\circ}$ Clinical Practice
}

\author{
Stroke prevention in atrial fibrillation: Commentary regarding the AAN's \\ evidence-based guideline update \\ Robert G. Hart and John W. Eikelboom \\ Neurol Clin Pract 2014;4;96-98 Published Online before print February 24, 2014 \\ DOI 10.1212/CPJ.0000000000000003
}

This information is current as of February 24, 2014

$\begin{array}{ll}\begin{array}{l}\text { Updated Information \& } \\ \text { Services }\end{array} & \begin{array}{l}\text { including high resolution figures, can be found at: } \\ \text { http://cp.neurology.org/content/4/2/96.full.html }\end{array} \\ \text { References } & \begin{array}{l}\text { This article cites } 14 \text { articles, } 1 \text { of which you can access for } \\ \text { http://cp.neurology.org/content/4/2/96.full.html\#\#ref-list-1 } \\ \text { This article has been cited by } 2 \text { HighWire-hosted articles } \\ \text { http://cp.neurology.org/content/4/2/96.full.html\#\#otherar }\end{array} \\ \text { Citations } & \begin{array}{l}\text { Information about reproducing this article in parts (figures, } \\ \text { its entirety can be found online at: } \\ \text { http://cp.neurology.org/misc/about.xhtml\#permissions }\end{array} \\ & \begin{array}{l}\text { Information about ordering reprints can be found online: } \\ \text { http://cp.neurology.org/misc/addir.xhtml\#reprintsus }\end{array}\end{array}$

Neurol Clin Pract is an official journal of the American Academy of Neurology. Published continuously since 2011, it is now a bimonthly with 6 issues per year. Copyright (C) 2014 American Academy of Neurology. All rights reserved. Print ISSN: 2163-0402. Online ISSN: 2163-0933.

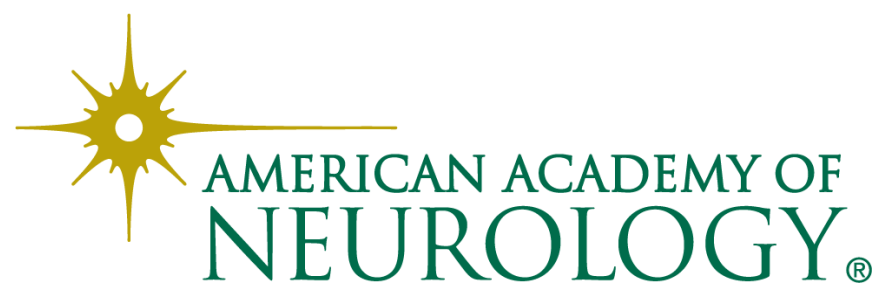

